\title{
A METHODOLOGY TO CHARACTERIZE MODAL DAMPING IN VIBRATING SYSTEMS: APPLICATION TO THE CASE OF GAS TURBINE COMBUSTION CHAMBERS.
}

\author{
Andrea Amedei ${ }^{1}$, Enrico Meli ${ }^{1}$, Andrea Rindi ${ }^{1}$, Egidio Pucci ${ }^{2}$ \\ 1Department of Industrial Engineering, Florence University, Italy \\ ${ }^{2}$ Nuovo Pignone Tecnologie - Baker Hughes, Italy
}

\begin{abstract}
The present paper proposes a methodology to characterize the modal damping ratio as a function of frequency in vibrating systems, with a focus on gas turbine combustion chambers. Proposed methodology correlates the modal damping ratio to the system modal eigenfrequencies, accurately considering the damping physical effects on the system dynamics and goes beyond the standard proportional damping hypothesis and similar techniques present in the literature.

The methodology has been compared under free-free conditions with standard damping ratio laws that can be found in the literature and which may lead sometimes to an overestimation of the real damping ratio values. Experimental data obtained through dedicated ping tests performed on two components of an industrial gas turbine annular combustion chamber have been used for the methodology validation: comparison between simulated and experimental results seems to be encouraging and the proposed methodology for modal damping ratio characterization turns out to be better, with respect to the standard ones, in reproducing not only the experimentally estimated damping law (as a function of the frequency), but also the typical Force Response Functions (FRFs) of the considered vibrating systems.

Finally, since the adopted procedure is numerically efficient and based only on low cost experimental techniques, it can be used for describing modal damping in vibrating systems since the early phases of the design, by increasing the design accuracy and reducing times and costs.
\end{abstract}

Keywords: Modal damping modelling, Modal damping experimental characterization, Combustion chamber, Gas turbine, FEM modelling.

\section{INTRODUCTION}

Nowadays, the need for detailed Finite Element Models (FEMs) and effective procedures to correlate simulated and experimental results is rapidly increasing, especially for vibrating systems. Such models and procedures turn out to be crucial both for investing critical physical phenomena and for the advanced design of high-performance machines.

One of the key factors in the correlation of FEM model results with experimental measurements is the characterization of the modal damping. Damping, indeed, deeply affects the dynamic behavior of vibrating systems and has to be carefully described [1][2]. More in detail, the estimation of the damping characteristic of machine components is important because it greatly influences the FRFs calculation and, consequently, the stress prediction. In fact, the stress calculation must be accurate (in terms of both mean and alternating stresses) to get a reliable assessment of the component fatigue behavior on the Goodman diagram and of its life / durability. Such methodologies are fundamental both during the design phase and for the verification / testing of the component itself.

The most important approaches in the literature to characterize the modal damping are based on the proportional damping hypothesis, starting from the Rayleigh damping [4][8][9] up to several generalizations of this hypothesis like the Caughey series and similar approaches [4][8][9][10][11]. At the same time, more general non-proportional damping models have been developed and applied to several and different scenarios. [12][13][14][15][16]. The proposed proportional and non-proportional damping modelling strategies have been compared to each other, for example, in [17][18].

Naturally, in the last decades, many experimental procedures have been developed as well to characterize and identify modal damping in many real applications [19][20] [21][22][23]. Such techniques are suitable both for proportional and non-proportional damping.

In this framework, the authors propose a simple but effective methodology to characterize the modal damping ratio as a function of frequency in vibrating systems, with focus on gas turbine combustion chambers (Figure 1). The proposed 
strategy for the modal damping characterization tries to correlate the modal damping ratio to the system modal eigenfrequencies by means of an optimization procedure directly based on experimental data. In this way, the physical effects of the damping phenomenon on the system dynamics are more carefully considered and the accuracy of the results can be improved with respect to standard approaches present in the literature, and especially the ones based on proportional damping [4][8][9][10][11]. An accurate estimation of the component damping characteristic in ambient condition allows indeed to reach a deeper understanding of the system behavior in terms of FRFs and, in particular, of its constraints. It represents a first fundamental step in the verification of the models, before to move to the hot condition damping verification, which can be performed in Full Annular Rig, as the one depicted in Figure 1. The verification of the structure damping in hot operating condition is more expensive, it can be performed later in the project development phase and cannot have the level of details can be obtained by dynamic behavior testing at component level. For these reasons, the damping characterization in ambient condition in an early development phase is an important verification step, to improve prediction reliability of both components dynamic behavior under different operating conditions and material stresses (mean stress and alternating stress values) for future structural and fatigue analyses. At the same time, computational time is not substantially increased, making the proposed strategy suitable for designing support since early phases of the development, for large scale FEM simulations, for sensitivity analyses and for the design of complex machines.

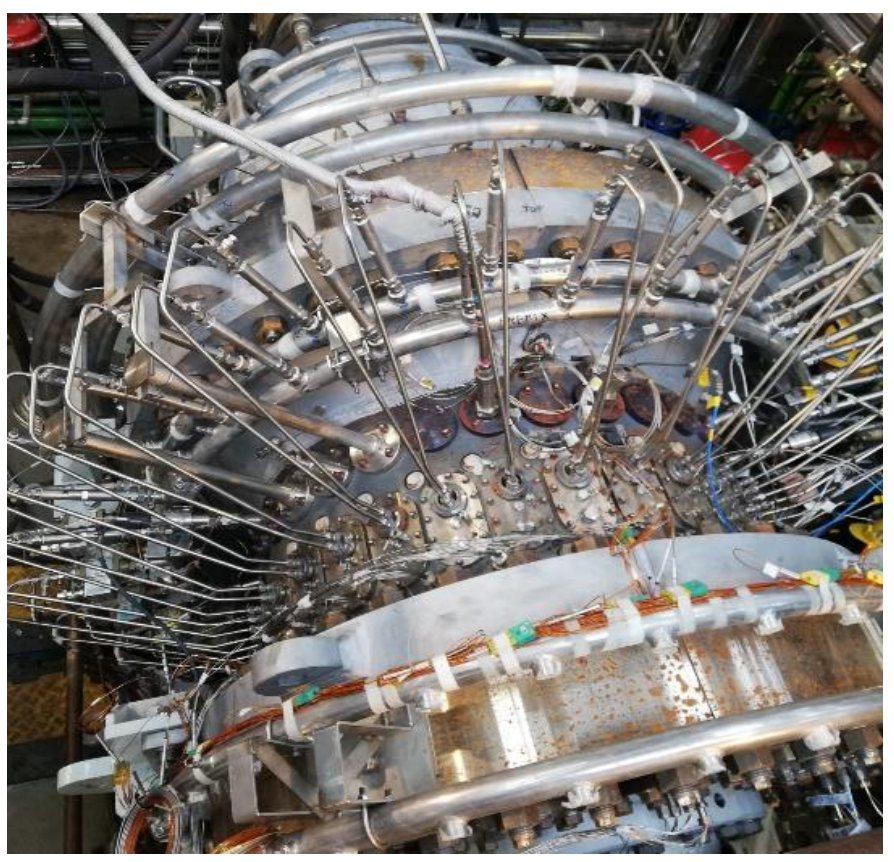

FIGURE 1: GAS TURBINE COMBUSTION CHAMBER TEST RIG (C) 2020 Baker Hughes Company - All rights reserved
Even if the proposed approach is quite general, by way of example, in this paper the authors are going to focus on two specific components of the considered gas turbine combustion chamber (the entire model is reported in Figure 2), i.e. the inner baffle (an air conveyor system for cold side convection improving, Figures 3) and the inner liner (Figure 4). This component is quite meaningful to highlight the differences between the proposed methodology and the standard ones.

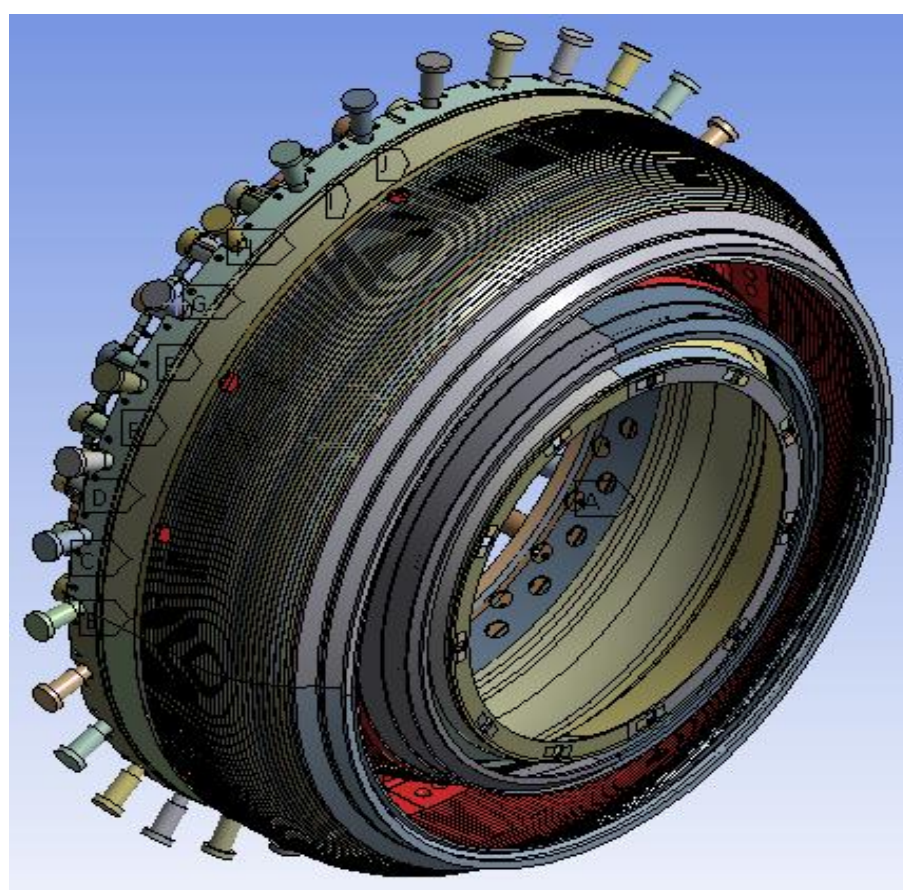

FIGURE 2: ENTIRE FE MODEL FOR THE COMBUSTOR (C) 2020 Baker Hughes Company - All rights reserved

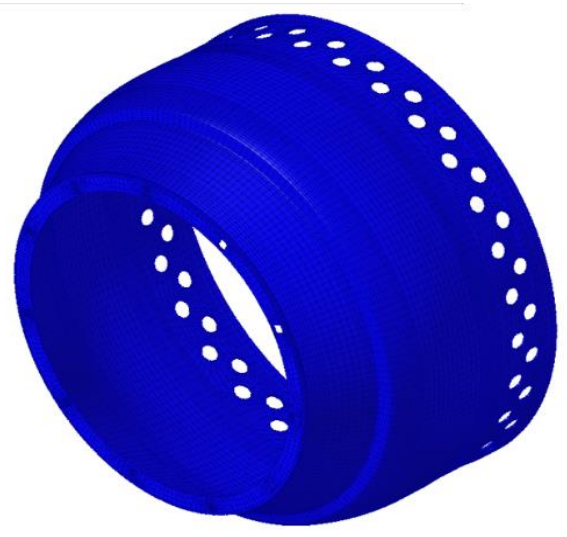

FIGURE 3: INNER BAFFLE OF COMBUSTION CHAMBER (C) 2020 Baker Hughes Company - All rights reserved 


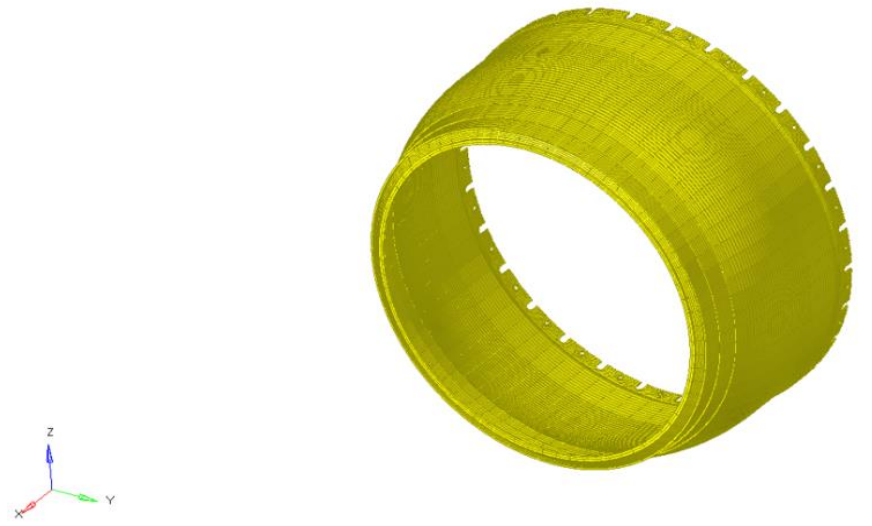

FIGURE 4: INNER LINER OF COMBUSTION CHAMBER (C) 2020 Baker Hughes Company - All rights reserved

Proposed methodology has been compared under free-free conditions with standard damping ratio modelling strategies that can be found in the literature and which may lead sometimes to an overestimation of the real damping ration values. The described approach has been also validated by comparing it to experimental data obtained through constrained ping tests performed on the inner baffle and the inner liner of the industrial gas turbine annular combustion chamber. The experimental tests have been carried out in collaboration with Baker Hughes, Nuovo Pignone Tecnologie [3].

\section{METHODOLOGY}

In this chapter the methodology followed by the authors to characterize the modal damping ratio in Finite Element Models is briefly described, while the different steps of the procedure will be analyzed more in details in the following chapters. The methodology can be summarized as follows:

1) first, the optimization procedure exploited to characterize the modal damping ratio as a function of the system modal eigenfrequencies is described. As it will be seen, such procedure is directly based on the experimental data (i.e. the measured modal damping ratio estimated from the experiments) to better consider the physical effects of the modal damping itself on the system dynamics.

2) then, components of the combustion chamber chosen as test-case (the inner baffle and the inner liner) are presented and the related Finite Element Models are developed and described.

3) subsequently, the experimental setup and the experimental results are presented for the components. The experimental tests consist of ping tests performed on the combustion chamber components under freefree conditions. These tests allow the estimation of the following experimental quantities: inertial properties, modal frequencies and modal shapes, harmonic response (including the required FRFs and the experimental modal damping ration characteristics).
4) the Finite Element Models are then validated in terms of inertial properties, modal frequencies and modal shapes without focusing, in this preliminary phase, on the role played by the modal damping.

5) finally, the proposed strategy for modal damping characterization is validated with focus on the effect of the modal damping. The numerical results obtained through the proposed approach and through the standard ones will be compared to each other and to experimental results. According to the previous points, in this phase the validation is performed in terms of harmonic response (including the required FRFs).

\section{MODAL DAMPING CHARACTERIZATION PROCEDURE}

To characterize the modal damping ratio as a function of the modal frequency, the starting point is the classic linear equation of motion coming from the Finite Element Model (in the time or in the frequency domain):

$$
\begin{array}{r}
M \ddot{\boldsymbol{q}}+C \dot{\boldsymbol{q}}+K \boldsymbol{q}=\boldsymbol{Q} \\
\left(-\omega^{2} M+j \omega C+K\right) \widetilde{\boldsymbol{q}}=\widetilde{\boldsymbol{Q}}
\end{array}
$$

where $\mathrm{M}, \mathrm{C}$ and $\mathrm{K}$ are the system mass, damping and stiffness matrices and $\boldsymbol{q}$ is the vector containing all the degrees of freedom. As usual, if $\psi$ is the modal matrix calculated by solving the undamped eigenvalue problem

$$
\begin{aligned}
M \ddot{\boldsymbol{q}}+K \boldsymbol{q} & =\mathbf{0} \\
\left(-\omega^{2} M+K\right) \widetilde{\boldsymbol{q}} & =\mathbf{0}
\end{aligned}
$$

it is known [1][2][4][8][9][10][11] that the original problem (1)-(2) can be diagonalized by introducing the modal variables

$$
\boldsymbol{q}=\psi \boldsymbol{p}
$$

if and only if the Caughey condition is satisfied:

$$
K M^{-1} C=C M^{-1} K
$$

In this case the substitution $\boldsymbol{q}=\boldsymbol{\psi p}$ leads to:

$$
\ddot{\boldsymbol{p}}+C_{d} \dot{\boldsymbol{p}}+K_{d} \boldsymbol{p}=\boldsymbol{P}
$$

where the diagonal matrices $C_{d}=\psi^{\boldsymbol{T}} C \psi$ and $K_{d}=$ $\psi^{\boldsymbol{T}} K \psi$ contain the modal frequencies $\omega_{i}$ and the modal damping ratios $\zeta_{i}$ of the system:

$$
\begin{gathered}
{\left[C_{d}\right]_{i i}=2 \omega_{i} \zeta_{i}} \\
{\left[K_{d}\right]_{i i}=\omega_{i}^{2}}
\end{gathered}
$$


and $\boldsymbol{P}=\psi^{\boldsymbol{T}} \boldsymbol{Q}$

Since the modal frequencies are already known from the solution of (3) and (4), once performed the diagonalization of the problem through (5) and obtained $\left[C_{d}\right]_{i i}$, the damping ratio $\zeta_{i}\left(\omega_{i}\right)$ can be easily calculated as a function of the modal frequencies $\omega_{i}$ by using (8). Naturally the elements $\left[C_{d}\right]_{i i}$ of the matrix $C_{d}$ and the resulting modal damping ratios $\zeta_{i}$ are function of the original matrix $\mathrm{C}$, which has mandatorily to satisfy the condition $(6): \zeta_{i}\left(\omega_{i}, C\right)$.

Particular subcases of this strategy [4][8][9][10][11] are the well-known Rayleigh proportional damping, where

$$
C=\alpha M+\beta K
$$

and the more general Caughey proportional damping, where

$$
C=M \sum_{i=0}^{N-1} \alpha_{i}\left(M^{-1} K\right)^{i} .
$$

in which $\mathrm{N}$ is the number of considered terms in the summation. In the first case only the parameters $\alpha$ and $\beta$ can be used to minimize the error between experimental and numerical damping ratio characteristics while, in the second one, all the parameters $\alpha_{i}$ can be exploited. The considered parameters can be calculated through standard least square based techniques [5][6]. The calculation of $\alpha$ and $\beta$ in (10) is simple but the accuracy is low because only two parameters are used to approximate the experimental damping ratio characteristics $\zeta_{i \exp }\left(\omega_{i}\right)$ through $\zeta_{i}\left(\omega_{i}, C\right)$. On the contrary, the accuracy obtained by means of (11) may be higher if a large number of terms $(\mathrm{N})$ is considered; however, in this case, the interpolation / approximation problem to determine $\zeta_{i}\left(\omega_{i}, C\right)$ may be often extremely ill-conditioned.

In this paper the authors tried to extend this approach by considering general damping matrices $C$ satisfying the conditions (6) and the energy dissipation condition

$$
\boldsymbol{q}^{\cdot T} C \dot{\boldsymbol{q}}>0
$$

The minimization of the error between experimental and numerical damping ratio characteristics $\zeta_{i}\left(\omega_{i}, C\right)$, $\zeta_{i \exp }\left(\omega_{i}\right)$ by using a larger class a damping matrices (the ones satisfying (6) and (12)) leads to a nonlinear optimization problem of the form:

$$
C_{\text {min }}=\underset{C \in C_{\text {damp }}}{\operatorname{argmin}} \sum_{i=1}^{N}\left|\zeta_{i}\left(\omega_{i}, C\right)-\zeta_{i \exp }\left(\omega_{i}\right)\right|
$$

$$
\zeta_{i}\left(\omega_{i}\right)=\zeta_{i}\left(\omega_{i}, C_{\min }\right)
$$

where, $C_{\text {damp }}$, is the class of damping matrices satisfying the conditions (6) and (12) and $\mathrm{N}$ is the number of considered modal frequencies. In this paper, the authors have initially chosen a simple tentative objective function to get a good tradeoff between accuracy and numerical efficiency. Furthermore, a simple choice of the objective function reduces the convergence problems as well.

The functional dependence of $\zeta_{i}$ on $\mathrm{C}$ may be quite complicated because, once the $\mathrm{C}$ matrix is known, one has to solve the classic eigenvalue problem $\operatorname{det}\left(s^{2} M+s C+\right.$ $K)=0 \quad$ to get the eigenvalue $s_{i}(C)=-\zeta_{i} \omega_{i} \pm$ $\mathrm{j} \omega_{i} \sqrt{1-\zeta_{i}}$ and, therefore, $\zeta_{i}\left(C, \omega_{i}\right)=-\operatorname{Re}\left[s_{i}(C) /\right.$ $\left.\left|s_{i}(C)\right|\right]$ (where $\left|s_{i}(C)\right|=\omega_{i}$ ).

Naturally, the expression $C_{d}=\psi^{T} C \psi$ together with (8) cannot be used to calculate $\zeta_{i}\left(\omega_{i}, C\right)$ because it would require the complete knowledge of the modal matrix $\psi$, which is numerically too expensive.

Analogously, it has to be observed that the trivial solution to the problem (13)

$$
C=\psi^{-T} C_{d e x t} \psi^{-1}
$$

where $\left[C_{\text {dext }}\right]_{i i}=2 \omega_{i} \zeta_{i \text { exp }}$ is not useful, due to the huge computation effort required to calculate the entire modal matrix $\psi$ and its inverse $\psi^{\mathbf{- 1}}$.

Consequently, the nonlinear minimization problem (7) has to be faced by following different ways and has to be solved approximately by exploiting suitable advanced numerical optimization methods [6][7] able to effectively work inside the matrix class $C_{d a m p}$.

The computational times of damping ratio estimation procedures based on optimization problem like the one described in (13) deeply depends on the required accuracy and may vary from some minutes up to some hours. Anyway, the computational efforts are quite reasonable, making the proposed strategy suitable for designing support since the early phases of development, for large scale FEM simulations, for sensitivity analyses and for the design of complex machines.

\section{TEST CASE DESCRIPTION AND FINITE ELEMENT MODEL}

In this chapter the main characteristics of the Finite Element models and of the meshes for the considered components (the inner baffle and the inner liner) are briefly summarized. Some details of the Finite Element models of the combustion chamber inner baffle and inner liner are represented in Figure 5 and 6. The main features of the meshes are reported in Table 1 and 2. 
Since the component dynamics is analyzed under free-free conditions, no mechanical constraints have been applied to the structure.

According to the experimental ping tests described in next chapter, once chosen the modal damping ratio characteristics (standard ones or new ones), the following quantities have been calculated through the Finite Element Models: inertial properties of the structure, modal frequencies and modal shapes, and harmonic response (including the required FRFs and the experimental). Results will be described in the chapter devoted to the validation of models and modal damping ratio characterization procedure.

The Finite Element model has been also used into the optimization procedure to calculate the proposed modal damping ratio characteristics described in the previous chapter.

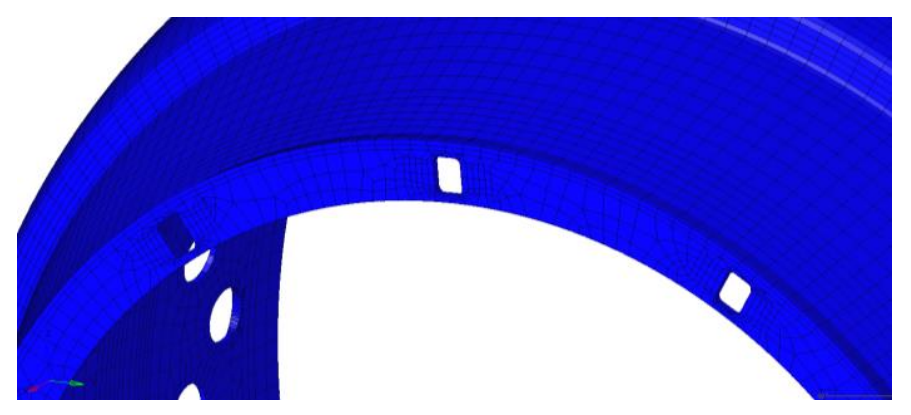

FIGURE 5: INNER BAFFLE FE MODEL AND MESH (C) 2020 Baker Hughes Company - All rights reserved

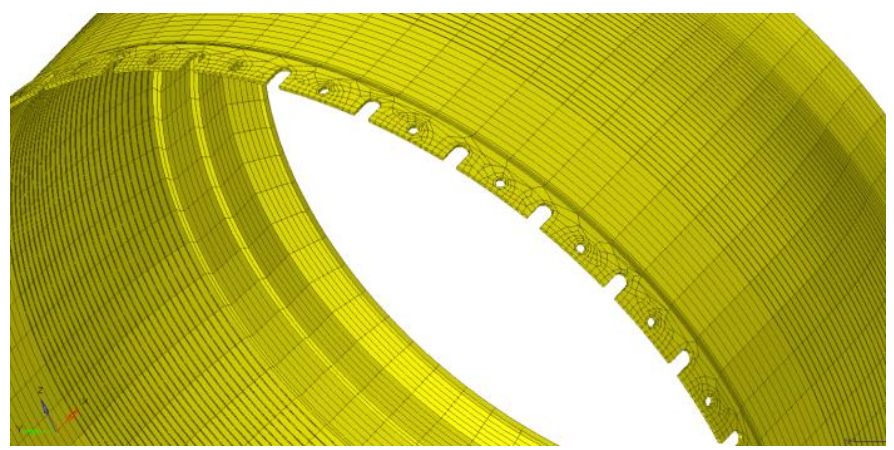

FIGURE 6: INNER LINER FE MODEL AND MESH DETAIL (C) 2020 Baker Hughes Company - All rights reserved

\begin{tabular}{|c|c|}
\hline \multicolumn{2}{|c|}{ INNER BAFFLE MESH } \\
\hline Finite Element Type & 3D 2 ${ }^{\text {nd }}$ order \\
\hline Number of Elements & $\mathbf{2 1 6 0 2}$ \\
\hline Number of Nodes & 135531 \\
\hline
\end{tabular}

TABLE 1: INNER BAFFLE MESH STATISTICS

\begin{tabular}{|c|c|}
\hline \multicolumn{2}{|c|}{ INNER LINER MESH } \\
\hline Finite Element Type & 3D 2 ${ }^{\text {nd }}$ order \\
\hline Number of Elements & 20816 \\
\hline
\end{tabular}

\begin{tabular}{|l|l|}
\hline Number of Nodes & 120611 \\
\hline
\end{tabular}

\section{TABLE 2: INNER LINER MESH STATISTICS}

\section{EXPERIMENTAL SETUP}

The experimental setup is aimed at estimating the most important physical quantities to study the vibrating behavior of the mechanical component: inertial properties, modal frequencies and modal shapes, and harmonic response (including the required FRFs and the experimental modal damping ratio characteristics).

The measurement points wireframe used during the experimental campaign performed on the inner baffle and the inner liner is reported in Figure 7 and 8 respectively.

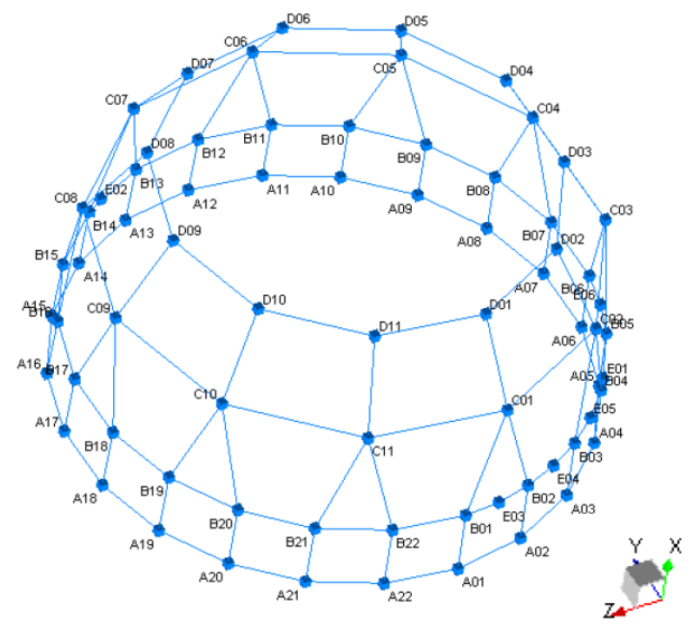

(a)

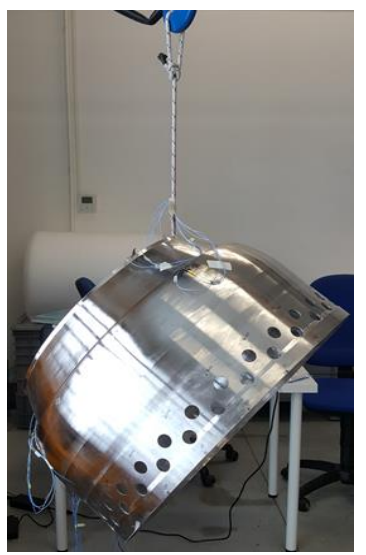

(b)

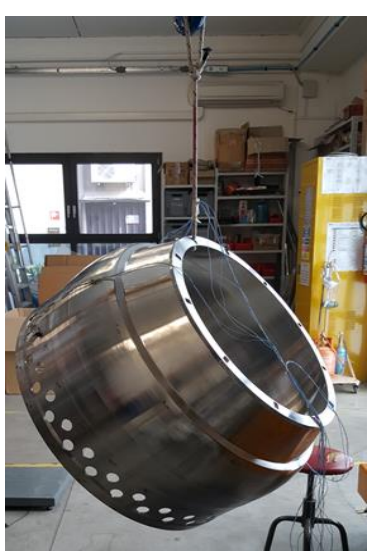

(c)
FIGURE 7: MEASUREMENT POINTS WIREFRAME FOR TEST ON INNER BAFFLE (a) AND EXPERIMENTAL SETUP (b)-(c) (C) 2020 Baker Hughes Company - All rights reserved 


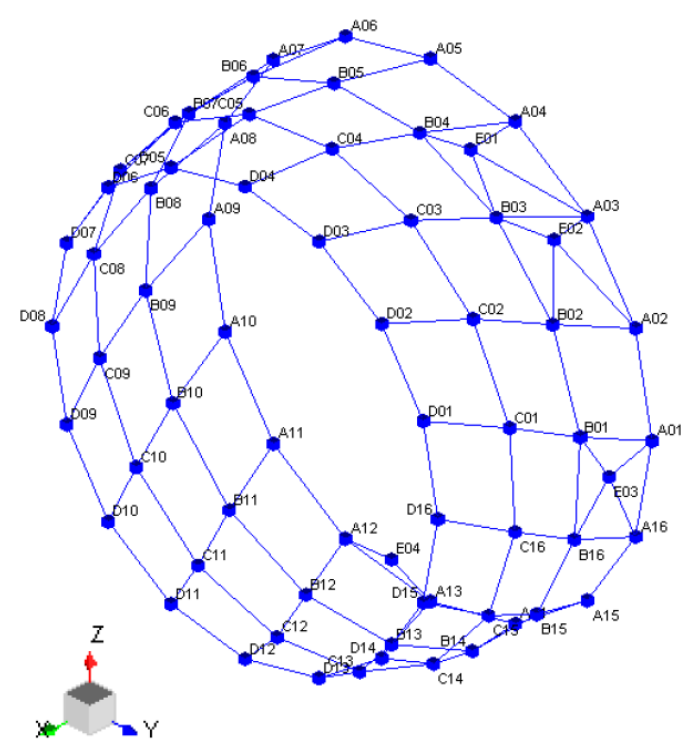

FIGURE 8: MEASUREMENT POINTS WIREFRAME FOR THE TESTS ON THE INNER LINER

(C) 2020 Baker Hughes Company - All rights reserved

The wireframe is divided into 5 sections (labelled as A, B, $\mathrm{C}, \mathrm{D}$ and $\mathrm{E}$ ) from outlet to inlet edge, whose number of points for inner baffle and inner liner are described in Table 3 and 4.

\begin{tabular}{|c|c|}
\hline Section & Number of Sensors \\
\hline A & 22 \\
\hline B & 22 \\
\hline C & 11 \\
\hline D & 11 \\
\hline E & 11 \\
\hline
\end{tabular}

TABLE 3: INNER BAFFLE PING TEST WIREFRAME POINTS DISTRIBUTION ALONG SECTION

\begin{tabular}{|c|c|}
\hline \multicolumn{2}{|c|}{ INNER LINER PING TEST POINTS } \\
\hline Section & Number of Sensors \\
\hline A & 16 \\
\hline B & 16 \\
\hline C & 16 \\
\hline D & 16 \\
\hline E & 4 \\
\hline
\end{tabular}

TABLE 4: INNER LINER PING TEST

WIREFRAME POINTS DISTRIBUTION ALONG SECTION

Into the sensor locations summarized in Table 3 and 4, the following sensors are placed: PCB Piezotronics 352C23 triaxial accelerometer.

The excitation has been given with an instrumented hammer PCB Piezotronics 086B05 in points B15 and A21 for the inner baffle and B09 for the inner liner, both in radial direction.

\section{PRELIMINARY VALIDATION OF THE FINITE ELEMENT MODEL}

In this chapter the Finite Element Models of inner baffle and inner liner are preliminarily validated in terms of inertial properties, modal frequencies, modal shapes and undamped FRF without focusing, in this preliminary phase, on the role played by the modal damping.

The validation in terms of inertial properties is summarized in Table 5 and 6 and, as expected, is quite good (see also Figure 9 and 10). The nominal design values of the inertial properties have been compared to the property values experimentally estimated starting from the experimental measurements obtained in the tests.

\begin{tabular}{|c|c|}
\hline Material & A \\
\hline Quantity & $\begin{array}{c}\text { Variation between nominal and } \\
\text { estimated value }\end{array}$ \\
\hline Density & 0 \\
\hline Young's Modulus & 28 \\
\hline Poisson's Ratio & 0 \\
\hline Mass & 0 \\
\hline C. of M. Position & 1 \\
\hline
\end{tabular}

TABLE 5: FINITE ELEMENT MODEL VALIDATION IN TERMS OF INERTIAL PROPERTIES FOR INNER BAFFLE

\begin{tabular}{|c|c|}
\hline Material & B \\
\hline Quantity & $\begin{array}{c}\text { Variation between nominal and } \\
\text { estimated value }\end{array}$ \\
\hline Density $\left[\mathrm{kg} / \mathrm{m}^{3}\right]$ & 0 \\
\hline Young's Modulus [Pa] & 11 \\
\hline Poisson's Ratio [-] & 0 \\
\hline Mass [kg] & 0 \\
\hline C. of M. Position [mm] & 3 \\
\hline
\end{tabular}

TABLE 6: FINITE ELEMENT MODEL VALIDATION IN TERMS OF INERTIAL PROPERTIES FOR INNER LINER 


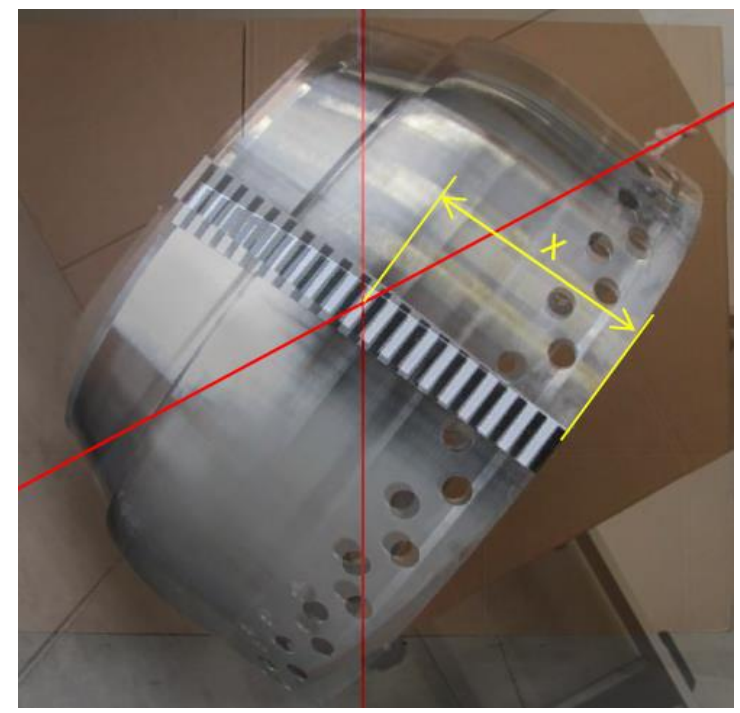

FIGURE 9: LONGITUDINAL X-POSITION OF THE CENTER OF MASS OF THE INNER BAFFLE

(C) 2020 Baker Hughes Company - All rights reserved

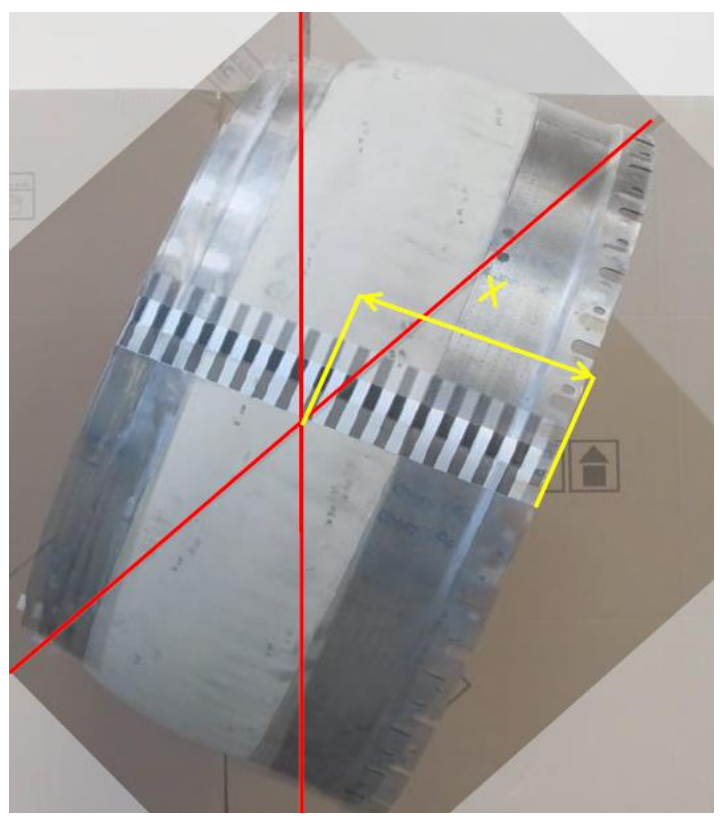

FIGURE 10: LONGITUDINAL X-POSITION OF THE CENTER OF MASS OF THE INNER LINER

(C) 2020 Baker Hughes Company - All rights reserved

More particularly, as regards the Young's modulus, the nominal value (first column of Table 5 and 6 ) is provided by the material supplier and it has been obtained by the material supplier through traction tests on specimens.

However, the turbine component considered in the paper has been manufactured through specific sintering processes and its mechanical characteristics may be different from the nominal ones. To be more confident on the component characteristics, the Young's modulus has been experimentally estimated as well, starting from the experimental measurements obtained in the tests. The experimentally estimated Young's modulus value has been reported in the second column of Table 5 and 6.

The correlation matrix AUTO-MAC [2], reported in Figure 11 and 12, indicates that experimental data are accurate. The results are satisfying in terms of modal frequencies and modal correlation as well. Modal frequencies are summarized in Table 7 and 8.

\begin{tabular}{|c|c|c|}
\hline $\begin{array}{c}\text { Mode } \\
\text { Number }\end{array}$ & Modal Shape & $\begin{array}{c}\text { Variation between numerical } \\
\text { and experimental frequencies }\end{array}$ \\
\hline 1 & 2 lobes inlet & $0 \%$ \\
\hline 2 & 3 lobes inlet & $1 \%$ \\
\hline 3 & 4 lobes inlet & $1 \%$ \\
\hline 4 & 2 lobes outlet & $1 \%$ \\
\hline 5 & 5 lobes inlet & $0 \%$ \\
\hline 6 & 6 lobes inlet & $0 \%$ \\
\hline 7 & 7 lobes inlet & $0 \%$ \\
\hline 8 & 3 lobes outlet & $2 \%$ \\
\hline 9 & 8 lobes inlet & $0 \%$ \\
\hline 10 & 4 lobes outlet & $1 \%$ \\
\hline 11 & 9 lobes inlet & $0 \%$ \\
\hline 12 & 10 lobes inlet & $0 \%$ \\
\hline 13 & 5 lobes outlet & Not Detected \\
\hline 14 & 11 lobes inlet & $0 \%$ \\
\hline 15 & 12 lobes inlet & $0 \%$ \\
\hline 16 & 6 lobes outlet & $0 \%$ \\
\hline
\end{tabular}

TABLE 7: VARIATION BETWEEN NUMERICAL AND EXPERIMENTAL MODAL FREQUENCIES AND SHAPES FOR THE INNER BAFFLE

\begin{tabular}{|c|c|c|}
\hline $\begin{array}{c}\text { Mode } \\
\text { Number }\end{array}$ & Modal Shape & $\begin{array}{c}\text { Variation between } \\
\text { numerical and experimental } \\
\text { frequencies }\end{array}$ \\
\hline 1 & 2 lobes inlet & $4 \%$ \\
\hline 2 & 3 lobes inlet & $1 \%$ \\
\hline 3 & 2 lobes outlet & $5 \%$ \\
\hline 4 & 4 lobes inlet & $2 \%$ \\
\hline 5 & 5 lobes inlet & $1 \%$ \\
\hline 6 & 3 lobes outlet & $4 \%$ \\
\hline 7 & 6 lobes inlet & $1 \%$ \\
\hline 8 & 7 lobes inlet & $1 \%$ \\
\hline 9 & 4 lobes outlet & $4 \%$ \\
\hline 10 & 8 lobes inlet & $1 \%$ \\
\hline 11 & 9 lobes inlet & $0 \%$ \\
\hline 12 & 5 lobes outlet & $1 \%$ \\
\hline 13 & 10 lobes inlet & $0 \%$ \\
\hline 14 & 6 lobes outlet & $2 \%$ \\
\hline 15 & 11 lobes inlet & $1 \%$ \\
\hline
\end{tabular}

TABLE 8: VARIATION BETWEEN NUMERICAL AND EXPERIMENTAL MODAL FREQUENCIES AND SHAPES FOR INNER LINER 


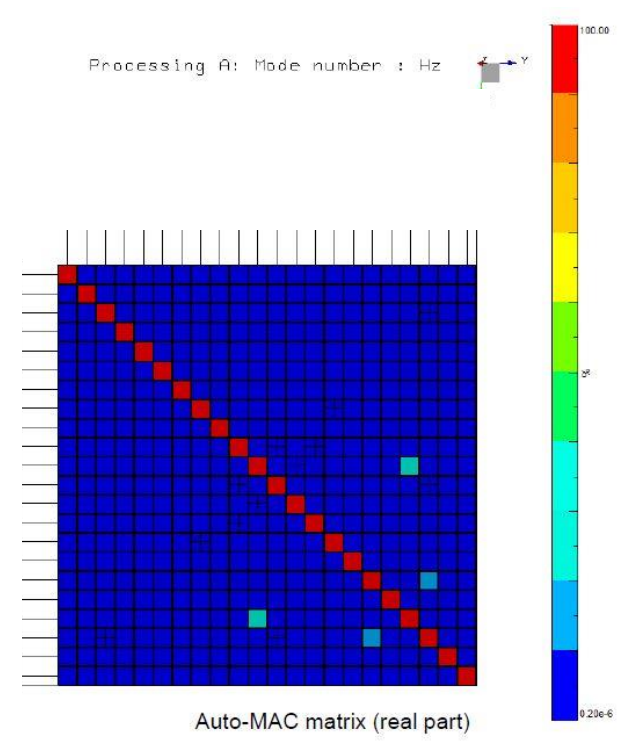

FIGURE 11: AUTO - MAC CORRELATION MATRIX FOR THE INNER BAFFLE

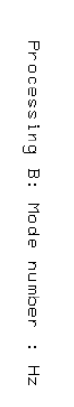

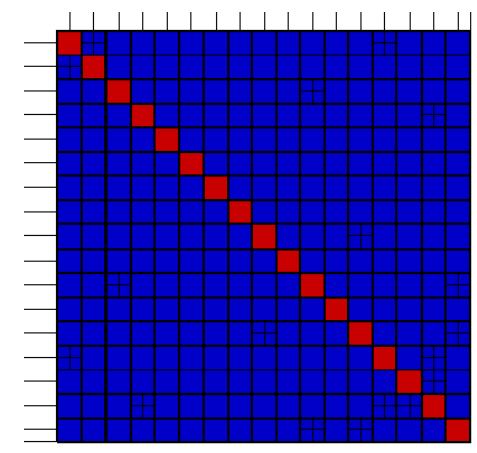

Auto-MAC matrix (real part)

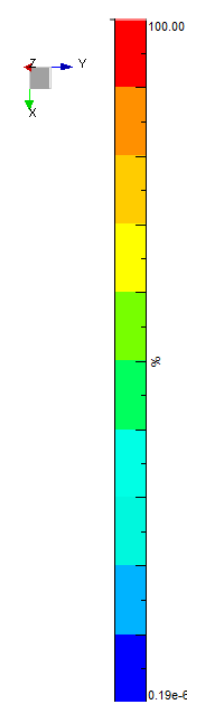

FIGURE 12: AUTO - MAC CORRELATION MATRIX FOR THE INNER LINER

Furthermore, by way of example, the comparison between experimental and numerical modal shapes is reported for some modes in Figure 13 and 14 ( 2 lobes inlet mode, 6 lobes inlet mode and 3 lobes outlet mode). Also, in this case the Finite Element Models seem to well reproduce the dynamic behavior of the real system.

Finally, to complete the pre-validation, a comparison between experimental FRF and calculated undamped harmonic response has been carried out as well (sampling frequency equal to 0.1 $\mathrm{Hz}$ ). In Figure 15 and 16, it is possible to view the FRF plots.
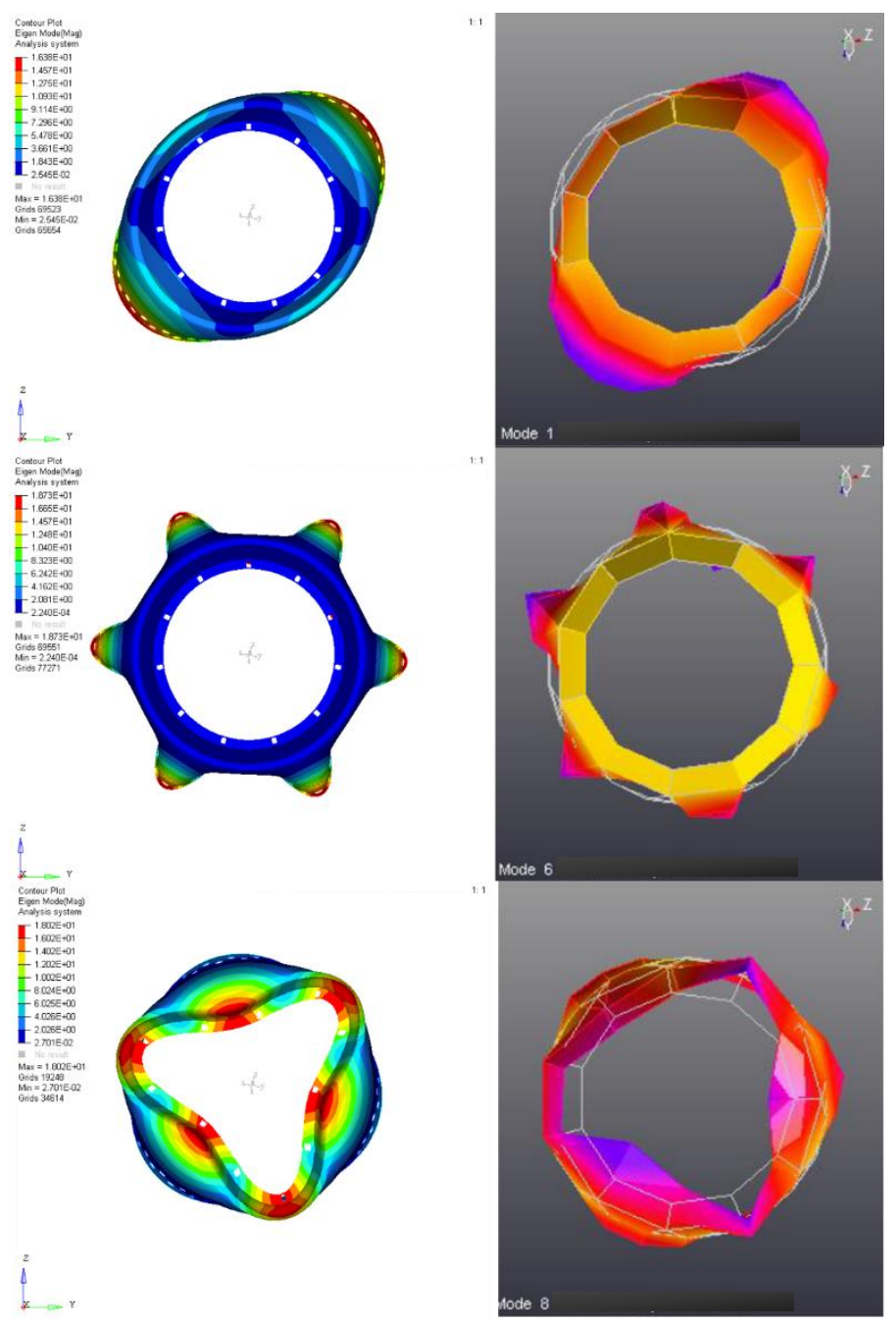

FIGURE 13: COMPARISON BETWEEN CALCULATED (ON THE LEFT) AND EXPERIMENTAL (ON THE RIGHT) MODAL SHAPES FOR THE INNER BAFFLE

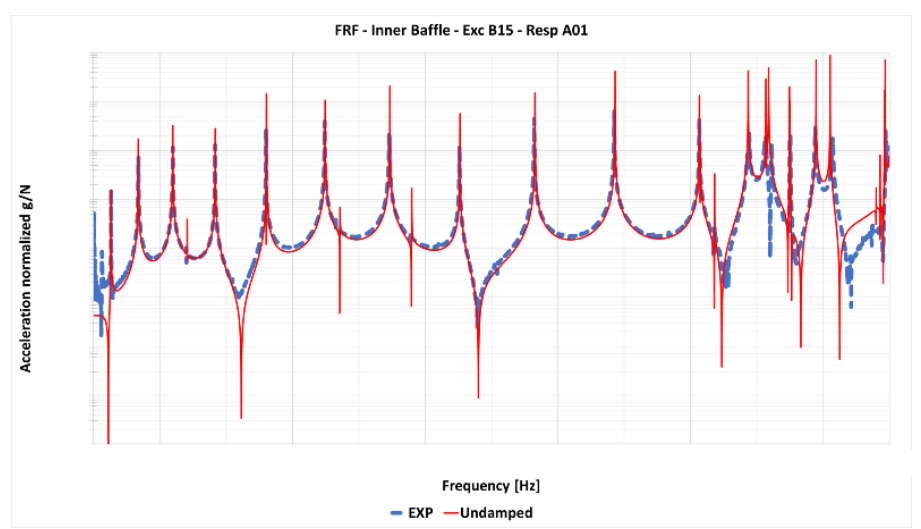

FIGURE 15: FRF COMPARISON: EXPERIMENTAL VS. UNDAMPED FEM FOR THE INNER BAFFLE 


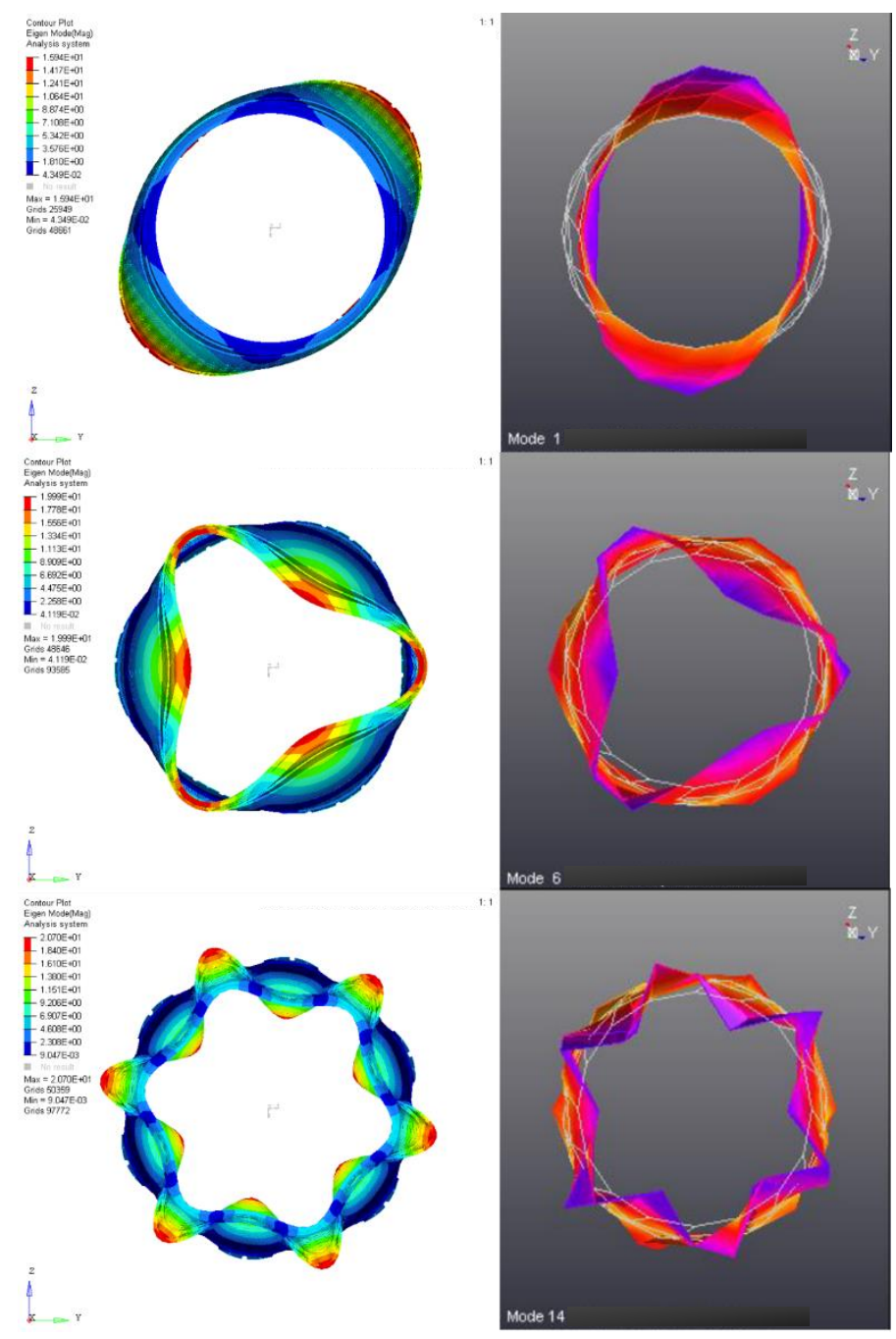

FIGURE 14: COMPARISON BETWEEN CALCULATED (ON THE LEFT) AND EXPERIMENTAL MODAL SHAPES (ON THE RIGHT) FOR THE INNER LINER

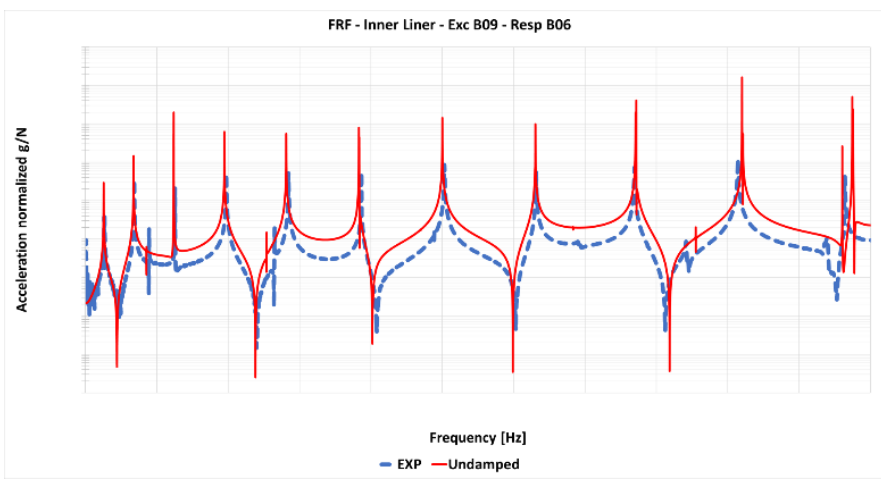

FIGURE 16: INNER LINER FRF COMPARISON: EXPERIMENTAL VS. UNDAMPED FEM

\section{VALIDATION OF THE MODAL DAMPING RATIO CHARACTERIZATION PROCEDURE}

In this chapter the proposed strategy for modal damping characterization is validated with focus on the effect of the modal damping. The numerical results obtained through the proposed approach and through the standard ones will be compared to each other and to experimental results. According to the previous points, in this phase the validation is performed in terms of harmonic response (including the required FRFs).

The comparison between the standard damping ratio characteristics (based on standard proportional damping approaches) and the damping ratio characteristics obtained through the proposed procedure is reported in Figure 17 for the inner baffle and in Figure 18 for the inner liner. The values of the numerical parameters involved in the standard proportional damping laws have been calculated by means of standard least squared based optimization algorithms [5][6]. The damping ratios are reported as a function of the modal frequencies.

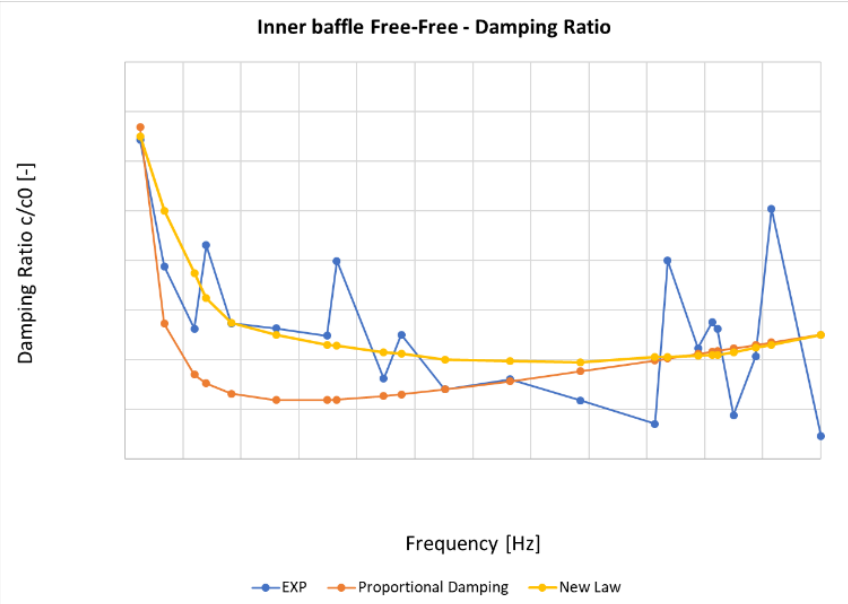

FIGURE 17: STANDARD DAMPING RATIO CHARACTERISTICS (BASED ON PROPORTIONAL DAMPING) AND OPTIMIZED ONE FOR THE INNER BAFFLE

Looking at Figures 18 and 19, it is possible to observe that the optimized damping ratio characteristic seems to better reproduce the physical trend of the experimental damping ratio law. The good behavior of the optimized damping ratio characteristic is also confirmed by the results of the harmonic response. More particularly, the comparison of the FRFs between input force, modelled as a Dirac impulse, and the acceleration normalized through the gravity acceleration is performed. Concerning the inner baffle, the input node on the wireframe exposed in Figure 7 is B15, while the response point in exam is A01. On the contrary, as regards the inner liner (Figure 8), the input node on the wireframe exposed in Figure 8 is B09, while the response point in exam is B06. 


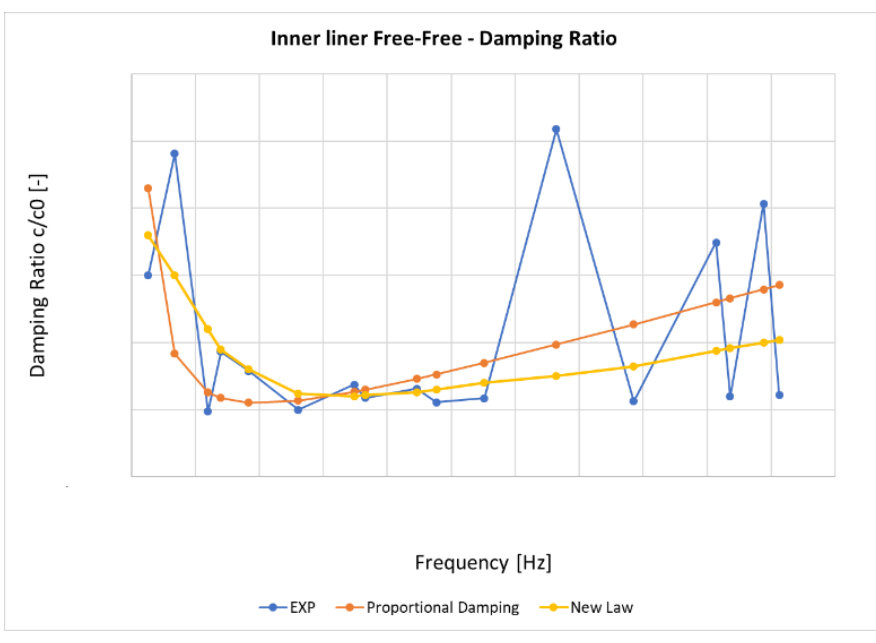

FIGURE 18: STANDARD DAMPING RATIO

CHARACTERISTICS (BASED ON PROPORTIONAL DAMPING) AND OPTIMIZED ONE FOR THE INNER LINER

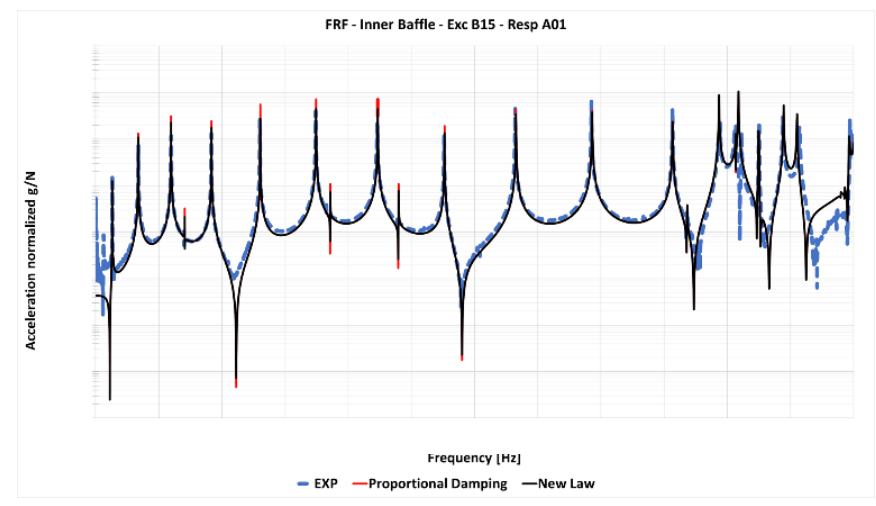

FIGURE 19: COMPARISON BETWEEN THE EXPERIMENTAL FRF AND THE FRFS OBTAINED THROUGH STANDARD DAMPING RATIO CHARACTERITICS AND OPTIMIZED ONE FOR THE INNER BAFFLE

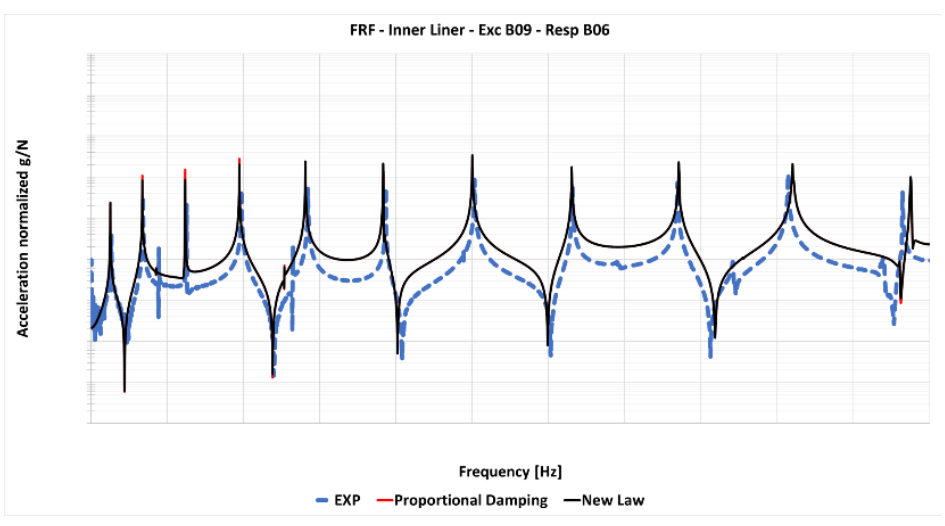

FIGURE 20: COMPARISON BETWEEN THE EXPERIMENTAL FRF AND THE FRFS OBTAINED THROUGH STANDARD DAMPING RATIO CHARACTERITICS AND OPTIMIZED ONE FOR THE INNER LINER
In Figures 19 and 20 the numerical results (in terms of FRFs) obtained through the proposed approach and through the standard ones are compared to each other and to experimental results.

In Figure 21, 22 and 23, 24 some parts of Figures 19, 20 have been properly zoomed to better highlight the zones where the main differences between standard and proposed damping ratio characterization procedures occur. These differences are particularly appreciable, for example, for the inlet 7 lobes mode and the outlet 3 lobes mode concerning the inner baffle, and for 4 lobes inlet mode and 10 lobes inlet mode as regards the inner liner. In these cases, a significant difference between the experimental FRF and the FRF calculated by using the proportional damping law is present especially in terms of modal frequencies and FRF amplitude.

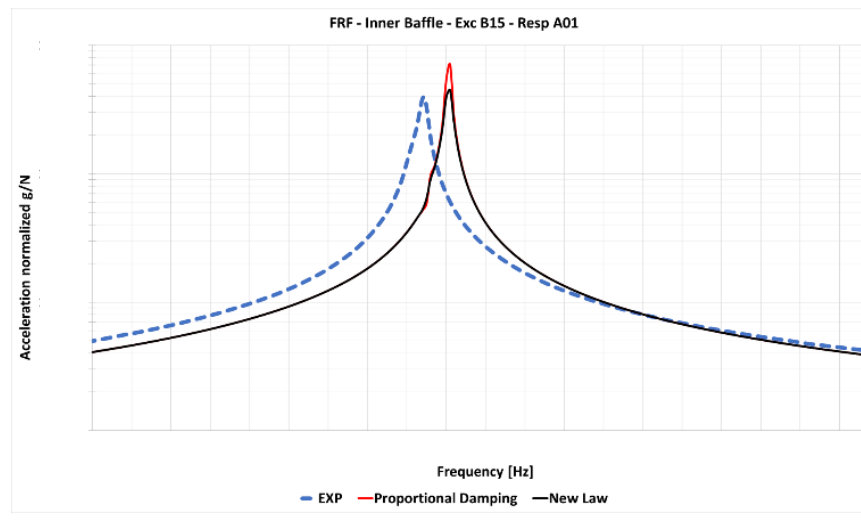

FIGURE 21: ZOOM OF THE FRFS COMPARISON FOR THE INNER BAFFLE.

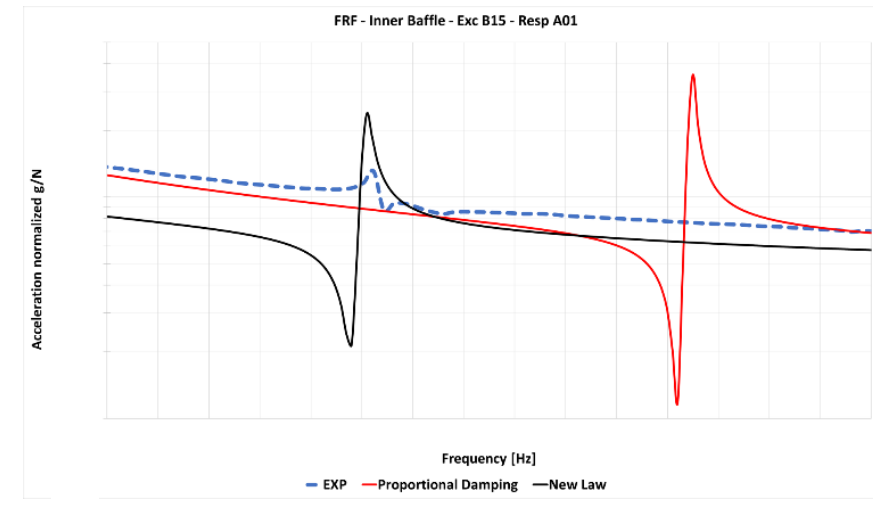

FIGURE 22: ZOOM OF THE FRFS COMPARISON FOR THE INNER BAFFLE. 


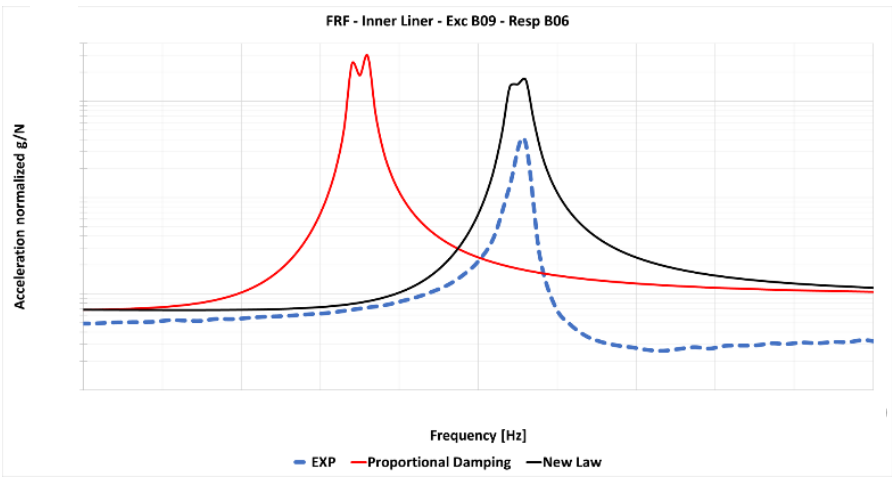

FIGURE 23: ZOOM OF THE FRFS COMPARISON FOR THE INNER LINER.

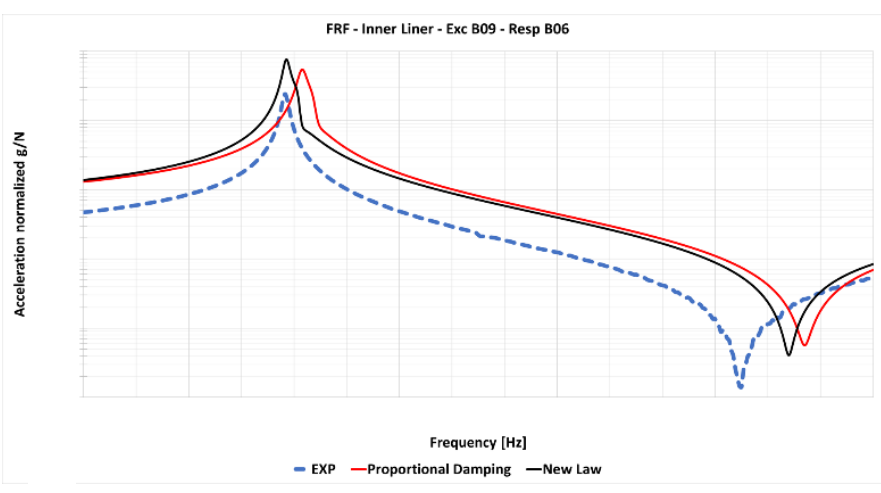

FIGURE 24: ZOOM OF THE FRFS COMPARISON FOR THE INNER LINER.

As it can be observed, the FRF calculated through the optimized damping law turns out to be more accurate than the one evaluated by means of the standard proportional damping approaches in reproducing the experimental FRF trend.

\section{CONLUSIONS AND FURTHER DEVELOPMENTS}

In this work the authors have presented a methodology to characterize the modal damping ratio as a function of frequency in vibrating systems, with focus on gas turbine combustion chambers. More particularly, the proposed methodology aims at accurately correlating the modal damping ratio to the system modal eigenfrequencies and improve the standard approaches which can be found in the literature (proportional damping hypothesis and similar techniques) by using advanced optimizations techniques and a more extended class of possible damping matrices $\mathrm{C}$. The proposed strategy and the related optimization directly rely on experimental data to better describe the physical effects of the damping phenomenon on the system dynamics.

The proposed strategy has been compared under free-free conditions with standard damping ratio laws that can be found in the literature and which may lead sometimes to an overestimation of the real damping ration values. The described approach has been also preliminarily validated by comparing it to experimental data obtained through ping tests performed on two specific components of an industrial gas turbine annular combustion chamber.

The comparison between simulated and experimental results seems to be encouraging and the proposed methodology for modal damping ratio characterization turns out to be better, with respect to the standard ones, in reproducing not only the experimentally estimated damping law (as a function of the frequency) but also the typical Force Response Functions (FRFs) of the considered vibrating systems.

Finally, since the adopted procedure is numerically efficient and based only on low cost experimental techniques, it can be used for describing modal damping in vibrating systems since the early phases of design, by increasing the design accuracy and being a time and cost-effective methodology.

Even if the preliminary results are encouraging, much work remains to be done and many future developments are planned. More particularly, new and more accurate objective functions will be considered in the optimization procedure required to estimate the damping characteristics. In this way, the nature of the damping coefficient will be more deeply explored and understood. At the same time, from an experimental viewpoint, the proposed strategy will be applied to new critical machine components to refine the procedure and improve its reliability.

\section{ACKNOWLEDGEMENTS}

The authors would like to thank all the colleagues from Baker Hughes, Nuovo Pignone Tecnologie for their contribution to this work and their support during the whole research activity.

\section{REFERENCES}

[1] M. Friswell, J. Penny, S. Garvey, A. Lees. Dynamic of rotating machines, Cambrigde Press, 2010.

[2] D. Ewins. Modal testing: theory, practice and applications. RSP Press, 2000.

[3] A. Amedei, E. Pucci, Dynamic analysis of NovaLT12 combustor, Internal Report of Baker Hughes, Nuovo Pignone, 2019.

[4] T. Caughey, M. O'Kelly, Classical normal modes in damped linear dynamic systems, Transaction of ASME, Journal of Applied Mechanics, 32, pp. 583-588, 1965.

[5] C. Kelley, Iterative Methods for Linear and Nonlinear Equations. Philadelphia PA, USA: SIAM; 1995.

[6] J. Nocedal, S. Wright, Numerical Optimisation. Berlin, Germany, Springer Series in Operation Research; 1999.

[7] M. Macconi, B. Morini, M. Porcelli, Trust-region quadratic methods for nonlinear systems of mixed equalities and inequalities, Applied Numerical Mathematics, 59:5 (2009), pp. 859-876.

[8] T. Caughey, Classical normal modes in damped linear dynamic systems, Transaction of ASME, Journal of Applied Mechanics, 27, pp. 269-271, 1960. 
[9] T. Caughey, F. Ma, Complex modes and solvability of non-classical linear systems, Transaction of ASME, Journal of Applied Mechanics, 60, pp. 26-28, 1993.

[10] D. Newland, Mechanical Vibration Analysis and Computation, Longman, Harlow and John Wiley, New York, 1989.

[11] S. Chakrabarti, B. Bhattacharyya, M. Swamy, On simultaneous diagonalization of a collection of hermitian matrices, The Matrix and Tensor Quarterly, 29 (2), pp. 35-54, 1978

[12] Bellos, J. and Inman, D. J. (1990), Frequency response of non-proportionally damped, lumped parameter, linear systems, Transaction of ASME, Journal of Vibration and Acoustics, 112, pp. 194-201.

[13] Bhaskar, A., Mode shapes during asynchronous motion and non-proportionality indices, Journal of Sound and Vibration, 224 (1), pp. 1-16, 1999.

[14] Chung, K. R. and Lee, C. W., Dynamic reanalysis of weakly non-proportionally damped systems, Journal of Sound and Vibration, 111, pp. 37-50, 1986.

[15] Gawronski, W. and Sawicki, J. T., "Response errors of non-proportionally lightly damped structures", Journal of Sound and Vibration, 200 (4), pp. 543-550, 1997.

[16] Tong, M., Liang, Z., and Lee, G. C. (1994), An index of damping non-proportionality for discrete vibrating systems, Journal of Sound and Vibration, 174, pp. 37-55, 1994.

[17] Bandstra, J. P., Comparison of equivalent viscous damping in discrete and continuous vibrating system, Transaction of ASME, Journal of Vibration, Acoustics, Stress and Reliability in Design, 105, pp. 382-392, 1983.

[18] Nair, S. S. and Sing, R. (1986), Examination of the validity of proportional damping approximations with two further numerical indices, Journal of Sound and Vibration, 104, pp. 348-350, 1986.

[19] B'eliveau, J.-G. (1976), Identification of viscous damping in structures from modal information, Transaction of ASME, Journal of Applied Mechanics, 43, pp. 335-339, 1976.

[20] Pilkey, D. F. and Inman, D. J., Iterative approach to viscous damping matrix identification, in "Proceedings of the 15th International Modal Analysis Conference (IMAC)", volume 2, (pp. 1152-1157), 1997.

[21] Liu, K., Kujath, M. R., and Zheng, W., Quantification of non-proportionality of damping in discrete vibratory systems, Computer and Structures, 77 (5), pp. 557-569, 2000.

[22] Minas, C. and Inman, D. J., Identification of a nonproportional damping matrix from incomplete modal information, Transaction of ASME, Journal of Vibration and Acoustics, 113, pp. 219-224, 1991.

[23] Prells, U. and Friswell, M. I., "A measure of nonproportional damping", Mechanical System and Signal Processing, 14 (2), pp. 125-137, 2000. 